\title{
Research on seismic performance of the multi-storey steel frame structure with additional oil dampers
}

\author{
Wu Hao ${ }^{1, a}$, Qiu Jixiang ${ }^{2, b}$ \\ ${ }^{1}$ School of Civil Engineering and Architecture, Jiangsu University of Science and Technology, \\ Zhenjiang Jiangsu, 212000, China. \\ ${ }^{2}$ School of Civil Engineering and Architecture, Jiangsu University of Science and Technology, \\ Zhenjiang Jiangsu, 212000, China. \\ a1050206989@qq.com, b906600287@qq.com
}

Keywords: Oil dampers. Damping multiples. Time history analysis. Damping effect.

Abstract. Based on the study of the multi-storey steel frame structure with additional oil dampers and consider composed of viscous coefficient $C_{1} 、 C_{2}$ with bilinear systems, vibration differential equations and computer programs are established. Taking damping multiples $n$ as a parameter for elastic-plastic time history analysis, change rules of the particle displacement 、 the absolute acceleration response value and the oil damper energy reaction are discussed ${ }^{[1]}$.

\section{Introduction}

Seismic action is equal to the input of vibration energy on the structure. Buildings under seismic action, therefore, should have sufficient energy dissipation capacity in order to avoid damage. Energy dissipation structure is that some non bearing members(such as bracing, shear wall, connectors, etc.) are designed to energy dissipation members or install energy dissipation device in a portion of the structure(space, node and connecting seam, etc.).This structure protects the main structure and components from damage and ensures the safety in strong earthquake. The oil damper is a kind of energy dissipation device which has superior performance, simple structure, convenient production. The oil damper has the advantages of small volume, large energy absorption, good damping effect, high efficiency, low price, good durability and so on. It has been shown that energy dissipation effect is very obvious and the damper has wide application prospect ${ }^{[2]}$.

\section{Analysis of structure with additional oil dampers}

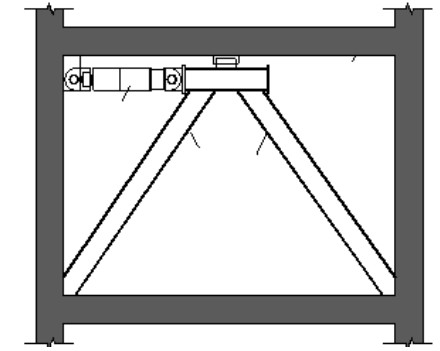

Fig.1 Additional oil damper structure diagram

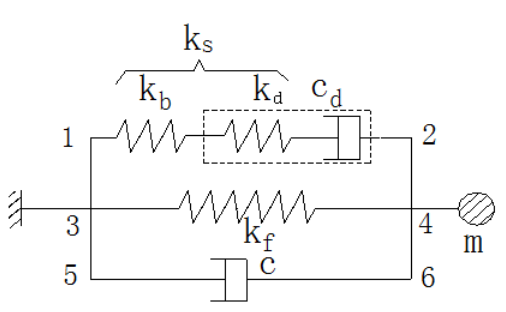

Fig.2 Additional oil dampers structural analysis model

The research object of this article is a multi-storey structure with additional oil dampers ${ }^{[3]}$.Figure 1 shows the connecting way of oil damper. Figure 2 shows analysis model of additional oil dampers structural. Among them,1-2 segment represents attached system of oil damper and series of bracing, $k_{b}$ represents the horizontal bracing lateral stiffness, $k_{d}$ represents the internal stiffness of oil damper,$c_{d}$ represents internal viscous damping coefficient of oil damper, $k_{s}$ represents sum of support stiffness and internal damper stiffness. Its value is: 


$$
k_{s}=k_{b} k_{d} /\left(k_{b}+k_{d}\right)
$$

(1)

In this formula, $k_{d}=\theta c_{d}, \theta$ is internal stiffness coefficient, usually takes $4.5 \sim 18(1 / \mathrm{s}) .3-4$ segment represents the main part of structure (beams and columns), among them, $k_{f}$ represents the lateral stiffness of structure. In the 5-6 segment, $c$ represents the damping coefficient of structure, $m$ is $\operatorname{mass}^{[4]}$.

The vibration differential equation of multi-storey structure with additional oil dampers in strong earthquake is:

$$
M d \mathfrak{d}+C \hat{x}+K_{F} x+F_{C}=M d \mathfrak{d}_{g}
$$

In this formula, $M$ represents the mass matrix of structure; $C$ represents internal viscous damping coefficient matrix of structure, using Rayleigh damper, $C=\alpha M+\beta K ; K_{F}$ represents lateral stiffness matrix of structure with additional oil damper, its value is $K_{F}=K_{f}+K_{s} ; F_{C}$ represents damping force of additional system. $x, x_{g}$ represents the displacement, velocity and acceleration of structure. ${ }_{g}$ represents ground acceleration.

\section{Principle Analysis}

In this paper, we assume that structure under seismic loading is always in a state of elastic deformation.The lateral stiffness is $k_{f}$, damping ratio is 0.02.Internal elastic stiffness of oil damper is $k_{d}$, the plastic stiffness is zero.Lateral stiffness of the bracing in series with the damper is $k_{b}$. Assume that $k_{b}$ is much greater than $k_{d}$. According to equation (2), $k_{s}$ is determined by $k_{d}$.

Viscous coefficient $C_{d}$ used in this paper is bilinear systems which is composed of the first, second viscous coefficient $C_{1}, C_{2}$ (Figure 3, dup 1 is the yield velocity of the viscous unit). $C_{2}=p C_{1}$, ( $p$ is the second viscous coefficient ratio). When the velocity of viscous unit reaches the yield velocity, its viscous coefficient will be $C_{2}$.

In this paper, viscous coefficient of structure with additional oil dampers is taken as a parameter. Its value is $C_{1}=10 \mathrm{n}(\mathrm{kN} \cdot(\mathrm{s} / \mathrm{cm}))$ and $n$ ( referred damping multiply) changes from 1 to 5.Assume that $C_{2}=q C_{1}, q=0.05, k_{d}=\theta C_{1}, \theta$ is the internal stiffness coefficient and $\theta=10$. Therefore,there is proportional relationship between the internal stiffness of oil damper $k_{d}$ and damping multiply $n$.

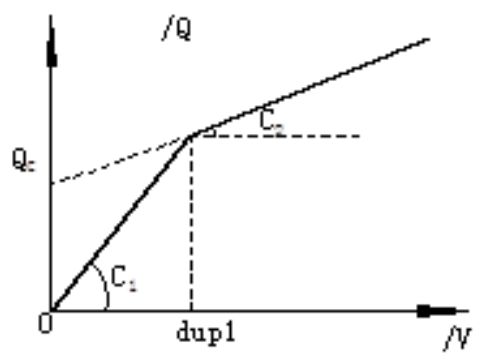

Fig.3 Damping force - velocity relationship

\section{Displacement reaction}

Under three earthquakes(sine wave, which period is $1.0 \mathrm{~s}$; frequent earthquake, which peak acceleration is $70 \mathrm{~cm} / \mathrm{s}^{2}$; rare earthquake, which peak acceleration is $400 \mathrm{~cm} / \mathrm{s}^{2}$ ), time history analysis of the original structure and structure with additional oil damper was carry on and we compared the results $^{[5]}$.

In figure 4, the abscissa represents the maximum story drift of structure, the ordinate represents the number of structure layers. Taking damping multiply $n$ as parameter, compare the results of the original structure and the structure with additional oil damper. As we can see from the picture, the 
maximum story drift of the structure with additional oil damper is smaller than the original structure. When damping multiply of the structure with additional oil damper becomes larger, the maximum story drift is smaller. We can come to the conclusion that oil damper attached to the structure plays an important role in reducing the displacement. The more amount of additional damper is, the smaller story drift becomes, the damping effect is better.

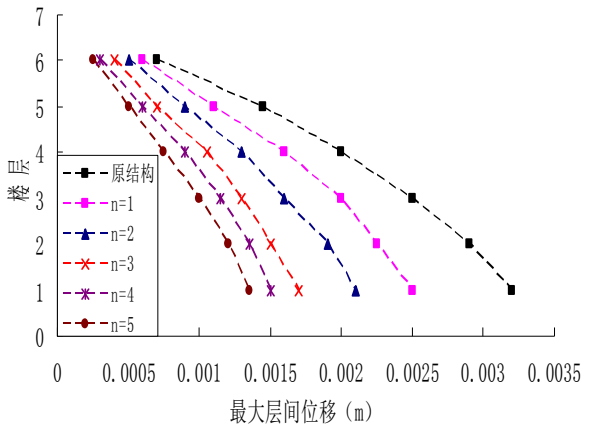

Multi earthquake

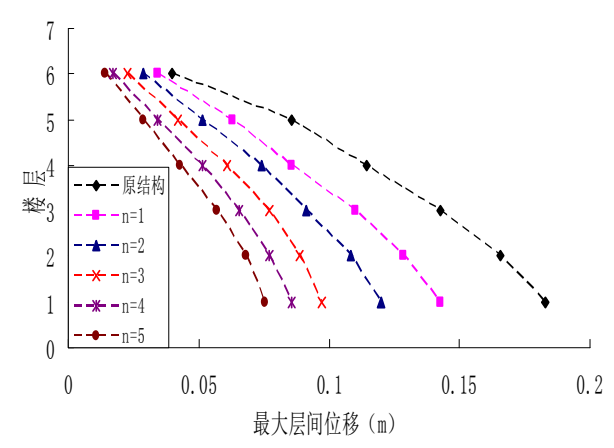

Rare earthquake

Fig.4 Displacement reaction

\section{The acceleration response}

In figure 5,the abscissa represents the maximum absolute acceleration of structure, the ordinate represents the number of structure layers. Taking damping multiply $n$ as parameter, compare the results of the original structure and the structure with additional oil damper. As we can see from the picture, the maximum absolute acceleration of the structure with additional oil damper is smaller than the original structure. When damping multiply of the structure with additional oil damper becomes larger, the maximum absolute acceleration is smaller. We can come to the conclusion that oil damper attached to the structure plays an important role in reducing the absolute acceleration. The more amount of additional damper is, the smaller absolute acceleration becomes, the damping effect is better.

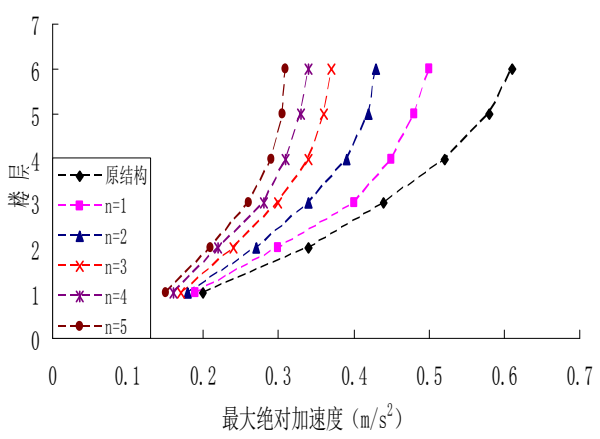

Multi earthquake

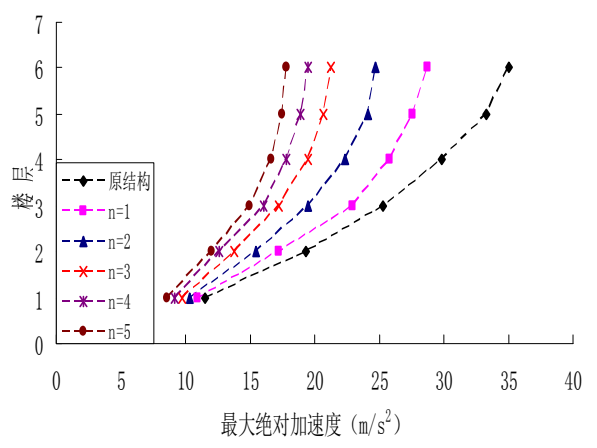

Rare earthquake

Fig.5 Acceleration response

\section{Energy response}

In figure 6 ,the abscissa represents time, the ordinate represents the energy consumed by the damper. Taking damping multiply as parameter, compare the results of the original structure and the structure with additional oil damper. As we can see from the picture, when damping multiply of the structure with additional oil damper becomes larger, the energy consumed by the damper becomes larger. Therefore, additional oil damper can control structural damage effectively, it can transfer damage to the replaceable additional oil dampers and protect the main structure effectively. 


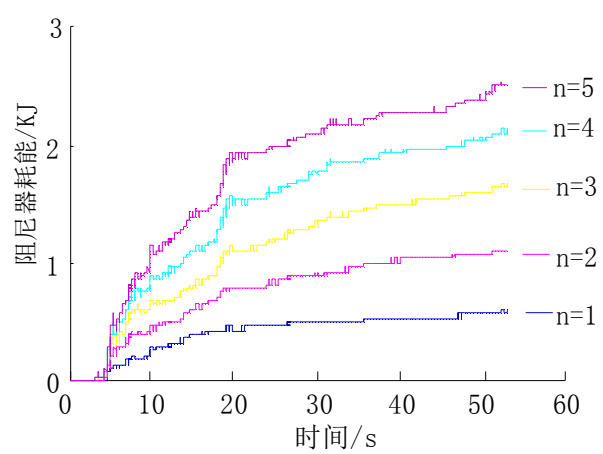

Multi earthquake

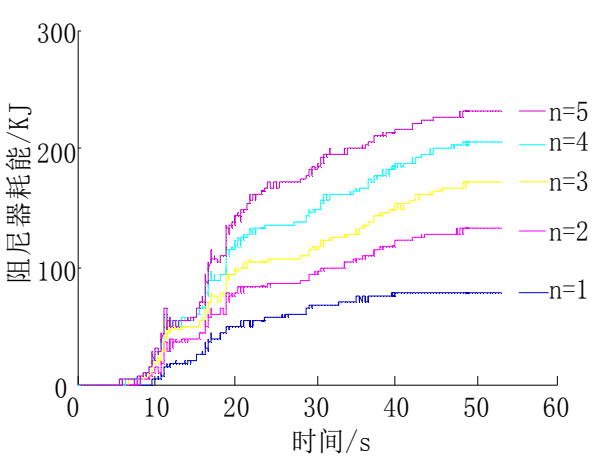

Rare earthquake

Fig.6 Oil damper energy reaction

\section{Conclusions}

The research object of this paper is a multi-storey steel frame structure with additional oil dampers.Conclusions are as follows:

(1) When damping multiply is larger, the internal elastic stiffness of additional damper $k_{d}$ is larger, story drift of structure is smaller, the damping effect is better.

(2) When damping multiply is larger, absolute acceleration of structure is smaller, the damping effect is better.

(3) When damping multiply is larger, the internal elastic stiffness of additional damper is larger, the energy consumed by the damper becomes more, the energy consumed by the structure becomes less.

In conclusion, the additional oil damper reduces story drift, absolute acceleration of structure and energy consumed by the structure, thus achieves good damping effect.

\section{References}

[1] Lin Jia,Wei Lu-shun,Liu Wen-guang, Wang Yu. Experimental study on mechanical properties of the oil damper [J].Science and Technology of Overseas Building Materials,2004,25:p92-94

[2] Pei Xing-zhu,Li Cheng-hao. Seismic design of building structures [M]. Beijing : China Electric Power Press , 2012: p59-61

[3] The association of vibration isolation structure in Japan. The design and construction of the manual of Passive suspension structure[M].Beijing:China Building Industry Press, 2008 : P28-31

[4] Ministry of Housing and Urban-Rural Development of the People's Republic of China. GB50009-2001.Load code for the design of building structures[S].Beijing: China building industry press,2001:p111-112

[5] Ministry of Housing and Urban-Rural Development of the People's Republic of China. GB50011-2010.Code for load of buildings[S].Beijing: China building industry press,2010:p42-44. 